\title{
The Integration of International Chinese Students Into Local Singaporean Community
}

\author{
Tran Nhi Bach Van, Duong Thi Hoang Yen, Xiao Juan, Sun Chenhui \\ James Cook University Australia (Singapore Campus), Singapore
}

\begin{abstract}
With the development of Chinese economy, a number of students choosing overseas schools for their studies are on the go and China has become a huge market of students for international education providers. However, some destinations for international education have declined in number of Chinese students in recent years, such as the US. More students tend to go to a country that does not only speak English, but also has the similar culture with their own country like Singapore. The objective of this paper is to find out the level of integration of international Chinese students into local Singaporean communities. Specifically, the research focuses on how international Chinese students interact with local Chinese communities and other local residents through activities, such as participating and volunteering in local Chinese events/festivals or public spaces. In addition, it also explores mutual feelings between the Chinese students and the local Singaporean community. Subsequently, the paper also examines about how friendships, institutions, and motivations influence Chinese students' integrations into the local community. Data were obtained primarily through surveys and face-to-face interview. Also, towards the conclusion, the paper gives some preliminary suggestions to engage more international Chinese students and bond them closer to the local community in order to create the best experience during their stay and study in Singapore.
\end{abstract}

Keywords: integration, interaction, Chinese students, engagement

\section{Introduction}

Since the implementation of Open Door Policy in 1978, China's economy was increasing rapidly, and Chinese government encouraged students to go abroad in order to strengthen the relationship among countries, as well as broaden the scholarship for international students (Tsang, 2001). A large number of students chose overseas schools as their studies. Based on UNESCO research, China was the biggest provider which occupied 14\% of international students (UNESCO, 2006). Merson (1989) determined that Chinese students believe that they can receive better quality of education and research compared with China-based students (Dimmock \& Leong, 2010). Students can experience a new life under an exotic atmosphere background that would broaden their horizon. Also, students think that if they graduate from prestigious universities overseas, they can get more opportunities in seeking jobs than local graduates (Dimmock \& Leong, 2010). Well-equipped facilities, good teaching and learning atmosphere as well as advanced education program in foreign universities deeply attract Chinese students. Consequently, more and more students tend to go to English-speaking country that has the similar culture background.

Tran Nhi Bach Van, Business Department, James Cook University Australia (Singapore Campus). Email: bachvan.trannhi@gmail.com. Duong Thi Hoang Yen, Business Department, James Cook University Australia (Singapore Campus).

Xiao Juan, Business Department, James Cook University Australia (Singapore Campus).

Sun Chenhui, Business Department, James Cook University Australia (Singapore Campus). 
Singapore is a destination that attracts many Chinese students to come. It is one of the world's safest and cleanest nations. For Chinese students, they chose Singapore universities to study due to cost, quality, and culture respectively (Dimmock \& Leong, 2010). First, studying in Singapore involves huge saving in tuition and living expenses as compared to studying and living in the US or the UK. According to Dimmock and Leong (2010), students who study and live in Singapore could save almost one-half costs compared with that in the UK. The second consideration is the quality. Singapore is regarding itself as an important education center in Asia (Tsang, 2001). There are three world-class universities in existence, including the National University of Singapore, the Nanyang Technology University, and the Singapore Management University (Embassy of the Republic of Singapore, 2012), which represent as the leading education level in the world. Combining academics, facilities, learning environment, and international recognition are the ideals for students to choose Singaporean universities, instead of choosing universities in the US or the UK (Dimmock \& Leong, 2010). The third is the consideration of culture. Culture factor plays a vital role in their decision-making. Cultural similarity brings advantages for Chinese international students to adapt easily to a new environment in Singapore (Tsang, 2001). Cultures of China and Singapore are similar because the biggest ethic group of Singapore is Chinese, which accounted for more than 76\% (Singapore Government, 2014), with a higher status of Chinese in Singapore and without discrimination. Also, Steele (2008) identified that using Mandarin or different mother tongues to communicate and access to most information in the host country is one of the advantages for Chinese students. Chinese students in Singapore not only learn knowledge from Western perspectives, but also can retain the Mandarin and ethnic Chinese traditional culture that will not make them estrange from their families when they go back home in the future.

Chinese students can adapt to a new environment effortlessly in Singapore. However, based on interviews by Steele (2008), there is no situation showing that international Chinese students went back to China because of inadaptation of life in Singapore. There are two challenges encountered by Chinese international students when they live in Singapore (Dimmock \& Leong, 2010). The first challenge is the teaching and learning environment. The Singaporean universities use English as the main instruction language. Most Mainland Chinese university students find language a major problem (Zhang, 2001). In addition, universities in Singapore highlight group work rather than individual work, and it also practises student-centered learning environment, instead of the teacher-centered learning environment in China (Dimmock \& Leong, 2010). Chinese students should communicate well with their team members from other countries. The second challenge is interaction. For Chinese students, because of their traditional customs and differences, they always tend to protect own privacy, even for their compatriots (Dimmock \& Leong, 2010). Chinese students like to stay at home rather than go outside with local students during holiday period, which results in the fact that Chinese students could not have many Singaporean friends in Singapore. Young generation is trying to adopt the western culture and value in Singapore (Song \& Lim, 2001). This generation is quite open and adopts modern lifestyles, which is quite different from Chinese young generation. International Chinese students and Singaporean students have different attitudes for activities. Most of Chinese students are not interested in the events organized by local students or do not find the same topic to share with the local students (Dimmock \& Leong, 2010). Chinese students always consider Mianzi (Dignity), Renqing (Favor), and Guanxi (Relationship) in social communication and interaction with local Singaporeans and other nationalities (Dimmock \& Leong, 2010). 
This paper focuses on the second challenge of international Chinese students in Singapore. It attempts to examine the level of integration of participants into not only local Chinese community but also other residents' community through activities, such as festival, volunteering, etc.. Also, how such interactions impact on their interacting performance will be considered.

\section{Literature Review}

\section{Chinese Diaspora in Singapore}

Since the late 1970s, the number of Chinese leaving their homeland has been increased significantly. There are about 30-35 million migrants from China over the world in the early 1990s (Lai, 2004). Lai (2004) determined that Fujian and Guangdong are the two provinces where most China's migrants came from with Hainan and the province of Guangxi also having a significant number of migrants. In recent times, the themes about "Chinese overseas" and "the Chinese Diaspora” were written in many books and journals and their use in conferences is increasing rapidly (Mackie, 2003). The Professor Wang Gungwu (as cited in Mackie, 2003, p. 1) identifies that "the citizens of Chinese descent who are living outside China can be seen as Chinese overseas or huaren”. However, Mackie (2003) also determined that many Chinese overseas have distaste for the word "Diaspora” because of different reasons.

Moreover, since China's Open Door Policy in the 1990s, many Chinese overseas expatriates have travelled and worked throughout the world, such as Southeast Asia, Northern America, and Australia. Some Chinese expatriates settle down as permanent residents, they pass over Chinese culture, history, values, and belief to the world and contribute to cross-culture. The traditional Chinese culture and customs are spread by Chinese Diaspora over the world. According to Mackie (2003), Chinese expatriates' frugality, hard work, and tenacity have derived by their traditional networks in business field. In addition, there are some related essential elements involved in their commercial success, such as Guanxi (Relationship) and Xinyong (Credit). Chinese expatriates always pass over their own unique values and attitude to host countries, whether in their overseas study, life, or businesses.

The descendants of earlier immigrants from China occupied $75 \%$ of the total population of Singapore. Therefore, many Chinese overseas believe that they will receive many supports from locals as newcomers (Liu, 2014). Since the 1990s, in order to attract more talents as well as to increase population, Singapore has created many opportunities, such as offering scholarships for international Chinese students to study, do research, and work in Singapore after graduation (Liu, 2012; as cited in Liu, 2014). Together with the immigration policies and also the familiarity of culture, Singapore became one of the destinations attracting most Chinese emigration (Liu, 2014).

\section{Integration of Chinese Overseas in Host Community}

The communities in Southeast Asia have about 24 million ethnic Chinese. Khanna (2001) said that most of them are not willing to integrate with the culture of the country they immigrate to. However, when the policy of People's Republic of China (PRC) limited its citizens having dual nationality since 1955, it is widely agreed that the level of integration of overseas Chinese into their host societies has been growing up (Lai, 2004). Indeed, the level of integration and the values of overseas Chinese have started changing since 1955. The overseas Chinese have already adapted to the values of their host countries and "no longer think of themselves as expatriates” (Lai, 2004, p. 12). 
Lai (2004) pointed out that the degree of hospitality of host societies for Chinese migrants is distinct in every society and varies by different periods of time. Although there is a similarity in culture between Singapore and China, there are differences in many perspectives, such as political and economic structures (Tsang, 2001). Liu (2014) determined that a large number of Singaporean Chinese do not perceive those ethnically Chinese as the same as them. The ethnic-Chinese occupied most of the population of Singapore. According to the studies of Bun and Sing (2003), both Singaporean Chinese and also ethnic-Chinese from the Mainland China are trying to distinguish between each other. It can be seen that social distance exists in their community. Although there is a similarity in culture and physical appearance, "the migrant from China remains foreign” (Bun \& Sing, 2003, p. 173).

It is widely agreed that there is a need for both sides to enrich integration. Indeed, Singapore Government came up with many strategies, such as establishing the National Integration Council in 2009, enhancing the integration of newcomers into local community (Liu, 2014). Besides that, Singapore Government also has strategies to encourage local Chinese to learn Mandarin. This not only helps their Chinese local citizens maintain their cultural roots but also increases opportunities for the development of economy (Khanna, 2001). Therefore, enhancement of Chinese language education is one of the main concerns of Singapore Government. On the other hand, Chinese officials also play an important part in building relations between new immigrants and host community (Liu \& Ryan, 2011). In fact, the Diaspora becomes one of the political aspects that PRC concerned in their foreign policy. The PRC Government has its own policy aims to protect and guard Chinese people all over the world (Khanna, 2001).

\section{Attitudes and Values of Chinese Students in Overseas}

Paige (1990; as cited in Steele, 2008, p. 1) identified international students as "individuals who temporarily reside in a country other than their country of citizenship, in order to participate in international educational exchange as students". According to the research of Chinese students' participation, many Western university professors found the common phenomenon: "silent Chinese student", which explains the fact that the majority of international Chinese students without language confidence usually keep quiet during classes or extracurricular activities. Thus, this behavior impedes the interaction of international Chinese students with their teachers and peers restricting collaboration and limiting their educational achievement (Hodkinson \& Poropat, 2014).

However, another report presents a different view about the attitude and behavior of international Chinese students towards interacting with local communities. Although the level of integration of international Chinese students into host communities is not high, they are building bridges to connect their friends and families with host countries.

The VFR is related to Chinese students studying in the host countries' universities because the images of the host countries are recommended to friends and relatives as tourist destinations. The international Chinese students would play a tour guide role when their friends and relatives come to visit the host country (Liu \& Ryan, 2011). Consequently, the implication shows that through such cases, they get to know the country and its people better, reinforcing their relationship with local communities as well as contributing to the host countries in tourism. 
In the case of Singapore, according to Steele (2008), international Chinese students do not have any challenges to get along with the life and study in Singapore, in terms of homesickness, loneliness, lack of social support, and financial difficulty. Steele (2008) identified that most of them are using Mandarin - their mother tongue to communicate and access to study and activities in host country. Therefore, learning to speak English is a main issue they are dealing with, because local residents usually use Singlish and Mandarin to communicate with them (Steele, 2008). Moreover, the research identified that the similarity in culture brings advantages for international Chinese students to adapt to a new environment in Singapore.

\section{Methodology}

The purpose of this paper is to evaluate the integration of international Chinese students into Singaporean community through interaction in social events or local festivals. The hypotheses are as follows:

H1: International Chinese students cannot integrate well into local community because they focus more on studying rather than interacting with locals.

H2: Interaction between International Chinese students and Singaporean is associated with the feeling of lacking common things in habits and lifestyles.

H3: International Chinese students do not often take part in local festivals and social events such as volunteering because they think that they are not welcomed there.

H4: International Chinese students will interact more with locals and take part in many social events if they have an intention to work in Singapore after graduation.

To prove those propositions, this paper adopts quantitative research method by conducting two separate surveys for both international Chinese students and Singaporeans which were done in August 2014. Also, groups of international Chinese students were gathered for an in-depth interview to gain additional insight for this study. The questionnaire was created in English and divided into two sections. The first one is about general information asking for ethnicity, age, gender, and education. However, some information about the type of school, hometown, and staying period in Singapore is for international Chinese students only, while information about status, profession, and language is for Singaporeans only. This is because for the first studied subject, this paper purposely examines international Chinese students and those elements about type of school, hometown, and staying period in Singapore are closely related to our study. On the other hand, for Singaporeans, this paper aims to cover people from all walks of life; thus, we ask about profession. For languages, we aim to examine the link between the number of languages a Singaporean can speak with their sympathy or attitude towards international Chinese students. The second section includes 10 questions about the attitude and interaction between international Chinese students and local Singaporeans. Answers were measured based on a 5-point Likert scale, ranging from strongly disagree to strongly agree.

This paper conducts online surveys through Surveymonkey.com website from August 4, 2014 to August 16, 2014. In addition, printed surveys were also delivered within James Cook University, Singapore Management University (SMU), and Carlisle Hostel. Moreover, we also go to some entertainment places such as Ang Mo Kio Hub, Clark Quay, and Singapura Plaza to conduct this survey for Singaporeans. Moreover, a seminar of a group of 10 International Chinese students was held to discuss more about their feelings, their thoughts, and adaption into local community. Also, through this approach, some suggestions for better integration were studied and developed. The questions guiding the interview are: 
(1) Will you join the local festivals or social activities in Singapore, if you are invited by local friends?

(2) What kind of events or festivals do you like to take part in?

(3) Will you be more active in interacting with locals, if you have an intention to work in Singapore after graduation?

(4) Do you think your institution plays an important role in helping international Chinese students make a better integration into local community?

(5) Do you share some experience in working with Singaporean students?

(6) Do you have the sense of national affinity with local Chinese in Singapore? Why or why not?

(7) Which attributes motivate you to participate in social activities or local festivals?

On the other hand, this paper also adopts the qualitative research method for related document analysis. Specifically, secondary research on Chinese diasporas, attitudes, and values of Chinese tourists and students in overseas, as well as their interactions in overseas, was studied and mentioned in literature review to further support our study.

\section{Findings}

\section{Demographic Background of the Respondents}

Table 1 shows the demographic background of international Chinese students. When it comes to international Chinese students, participants were drawn from a sample of 217 international Chinese students, aged from 13 to 25 and above, studying at both private (88.63\%) and public schools (11.37\%) in Singapore. Among them, there were $39.35 \%$ males and $60.65 \%$ females. The range of age of $13-25$ and above was chosen because it is the school age and of consciousness issues. As a matter of fact, international Chinese students in primary schools are not fully aware of this issue. Most of the participants study at universities (87.56\%), while the rest were from secondary or high schools (3.23\%), from junior colleges (4.61\%), from polytechnics (1.84\%), and from institutes of technical education (2.76\%). In terms of age, the percentage of students aged between 13 and 16 is 1.39\%, aged between 17 and 19 made up 14.35\%, aged between 20 and 25 and above 25 accounted for 84.26\%. In addition, there were 203 students coming from Mainland China, which accounted for 94.5\% of international Chinese respondents. Most of them come from Guangdong provinces (36.5\%), followed by those from Beijing (24\%) and Fujian province (4\%). On the other hand, 14 students reported their hometown in other countries, including Indonesia, Taiwan, Malaysia, Hong Kong, and Macau, which accounted for $5.5 \%$.

According to Table 2, for Singaporean, among the sample of 105 participants, there were $44.05 \%$ males and $55.95 \%$ females. Considering by gender, $85.54 \%$ are single and $14.46 \%$ are married, aged between 13 and 65 and above. The level of education varies from primary (4.76\%), secondary or high schools (33.33\%), vocational institutions (10.71\%) to tertiary level (51.19\%). In addition, the occupancy of surveyed Singaporean is various, including student, retired, marketer, army officer, salesman, solution architect, etc.. In other words, this survey attempts to involve as many Singaporeans from all walks of life as possible to gain an additional insight of the studied issue. In terms of ethnicity, 8.57\% Malay, 4.76\% Indian, and $86.67 \%$ Chinese are involved in this survey for local Singaporeans. Among them, $48.19 \%$ can speak more than one language such as Mandarin, Cantonese, Malay, or Tamil. 
Table 1

Socio-demographic Profile of International Chinese Students Respondents

\begin{tabular}{llc}
\hline Variable & & $\%(N=217)$ \\
\hline \multirow{2}{*}{ Gender } & Male & 39.35 \\
& Female & 60.65 \\
\hline \multirow{2}{*}{ Age } & $13-16$ & 1.39 \\
& $17-19$ & 14.35 \\
& $20-25$ & 67.13 \\
& 25 and above & 17.13 \\
\hline \multirow{2}{*}{ Education level } & Primary/secondary or high schools & 3.23 \\
& Junior colleges & 4.61 \\
\multirow{2}{*}{ School } & Polytechnics & 1.84 \\
& Institutes of technical education & 2.76 \\
\multirow{3}{*}{ Place of residence in China } & Universities & 87.56 \\
& Private & 88.63 \\
& Public & 11.37 \\
\hline & Guangdong province & 36.5 \\
& Beijing & 24 \\
Other countries & Fujian province & 4 \\
& Others & 30 \\
\hline
\end{tabular}

Table 2

Socio-demographic Profile of Local Singaporean Respondents

\begin{tabular}{llc}
\hline Variable & & $\%(N=105)$ \\
\hline \multirow{2}{*}{ Gender } & Male & 44.05 \\
& Female & 55.95 \\
\hline \multirow{4}{*}{ Age } & $13-16$ & 19.05 \\
& $17-20$ & 20.24 \\
& $21-24$ & 21.43 \\
& $25-34$ & 23.81 \\
& $35-44$ & 7.14 \\
Education level & $45-54$ & 3.57 \\
& $55-64$ & 1.19 \\
& 65 and above & 3.57 \\
\hline \multirow{3}{*}{ Language } & Primary & 4.76 \\
& Secondary or high schools & 33.33 \\
& Vocational institutions & 10.71 \\
& Tertiary level & 51.19 \\
\hline \multirow{2}{*}{ Status } & English & 100 \\
& Mandarin & 34.94 \\
Ethnicity & Cantonese & 2.41 \\
& Malay & 9.64 \\
& Tamil & 1.20 \\
\hline & Single & 85.54 \\
& Married & 14.46 \\
\hline
\end{tabular}




\section{Attitudes of Singaporeans and International Chinese Students Towards Culture Similarity}

The results revealed that there were no significant differences between the international Chinese students and local Singaporeans in their attitudes about culture. Most of the international Chinese students who participated in this survey agreed that Singaporean Chinese shared a similar culture with Mainland Chinese, which made up for $60.47 \%$ (see Figure 2). Similarly, nearly 52.89\% Singaporean thought that Singaporean Chinese shared a similar culture with Mainland Chinese (see Figure 1). However, there is still a big gap of approximately $9 \%$ between the two studied subjects on this aspect. Thus, even though they both agree on the culture similarity between Chinese Singaporeans and Mainland Chinese, the percentage of international Chinese students was much higher than that of Singaporeans.

In fact, the responses show that there was equality in the number of international Chinese students who had neutral and strong feelings of belonging to the local Chinese community in Singapore, with both $43.54 \%$ (see Figure 2). Although 43.54\% made up a big proportion for agreement, the percentage of neutral opinion was the same. Moreover, there were about $11.49 \%$ of international Chinese students responding that they did not feel the sense of belonging to the local Chinese community in Singapore (see Figure 2).

Interestingly, in the same vein, not majority of Singaporeans recognized that international Chinese students constitute an important part of the local Singaporean community; just 36\% agreed on this idea and 36\% students put the neutral as their opinions (see Figure 1). In addition, there were another $21 \%$ of the Singaporeans who did not agree with this statement (see Figure 1). Consequently, there was not a high agreement on the sense of belonging. Again, the difference is around $9 \%$ between Singaporeans' and international Chinese students’ responses.

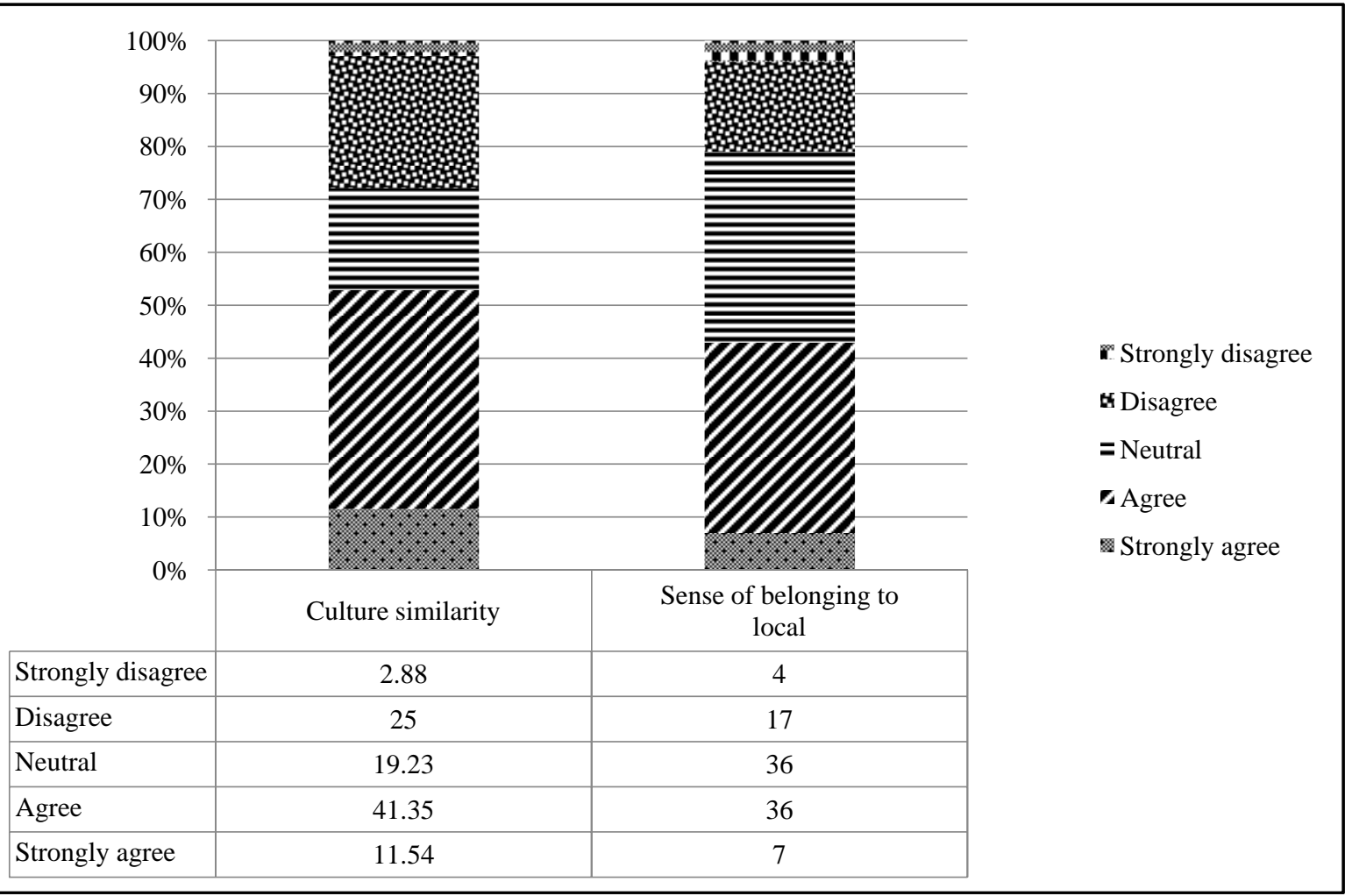

Figure 1. Culture similarity and sense of belonging from Singaporeans’ perspectives. 


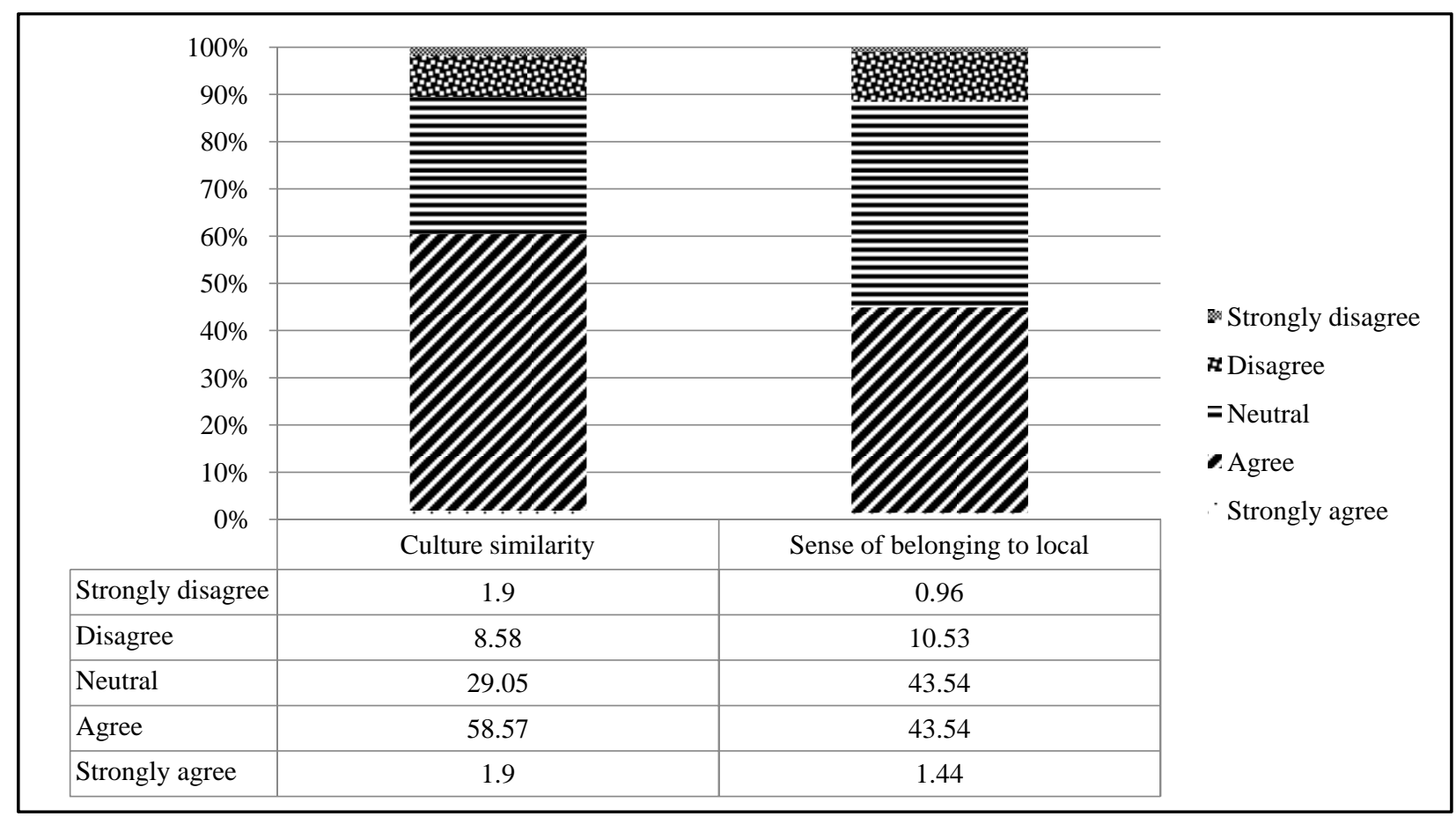

Figure 2. Culture similarity and sense of belonging from international Chinese students’ perspectives.

In terms of national affinity, through interviews, the paper explores that in the perceptions of international Chinese students and also local Singaporeans even Chinese Singaporeans, all of them thought that although China and Singapore were quite different in government structure and economic and social aspects, they still shared a similar culture. Moreover, Singapore owns a multi-ethnic society which includes Chinese, Malay, and Indian. Thus, for most international Chinese students, they did not feel the sense of national affinity with locals. Additionally, they preferred to gather in their own cliques with other international Chinese students with whom they could easily share familiarity.

In general, the result shows that the majority of participants from two sides both agreed that they shared many common things in culture. Nevertheless, both sides disagreed on the sense of belonging to local Chinese community and International Chinese students also did not feel the sense of national affinity with locals as well.

\section{Attitude of International Chinese Students and Singaporeans Towards Each Other}

For most international Chinese students, the proportion reached $67.46 \%$, which showed that it was easy to communicate with local Singaporeans as they were helpful and friendly of interaction (see Figure 4). About $50.49 \%$ of Singaporean respondents agreed that they had happy and comfortable feelings when interacting with international Chinese students (see Figure 3). Meanwhile, 59.4\% Singaporeans realized that more and more international Chinese students had been living nearby their residential areas. This fact appears to be a good opportunity for increasing the level of integration of international Chinese students into local community. In addition, 53.86\% international Chinese students believed that local Singaporeans were reliable companions when they worked together (see Figure 4). Also, almost 69\% Singaporean had the experience working together with international Chinese students in their study projects (see Figure 3). International Chinese students made a strong impression on local Singaporean about their hardworking characteristics. Some Singaporeans shared their experience in working with international Chinese students as follows: 
The Chinese international students always give me a hardworking impression. Although they have difficulty with their command of English language, they are very hardworking and willing to learn, regardless of the challenge presented to them. They are not afraid of voicing out even if they have to share their opinions in English.

From the results of the survey, it can be concluded that the locals who could speak more than one language, such as Mandarin and Cantonese, were more open and friendly to international Chinese students. In addition, they also felt sympathy for the challenges being faced by international Chinese students.

On the other hand, 50.49\% Singaporeans agreed that they could interact well with international Chinese students, and $46 \%$ Singaporeans had many Chinese international students as their friends (see Figure 3). Conversely, 39.9\% international Chinese students revealed that they did not have many local Singaporean friends and relatives in Singapore while 31.73\% had some (see Figure 4). Among them, most came from Guangdong or Fujian provinces. Having few local friends or relatives could result in the fact that more international Chinese students did not feel warm welcome, openness, and acceptance of the local Chinese community. As a result, the link between them and local activities has not been created successfully.

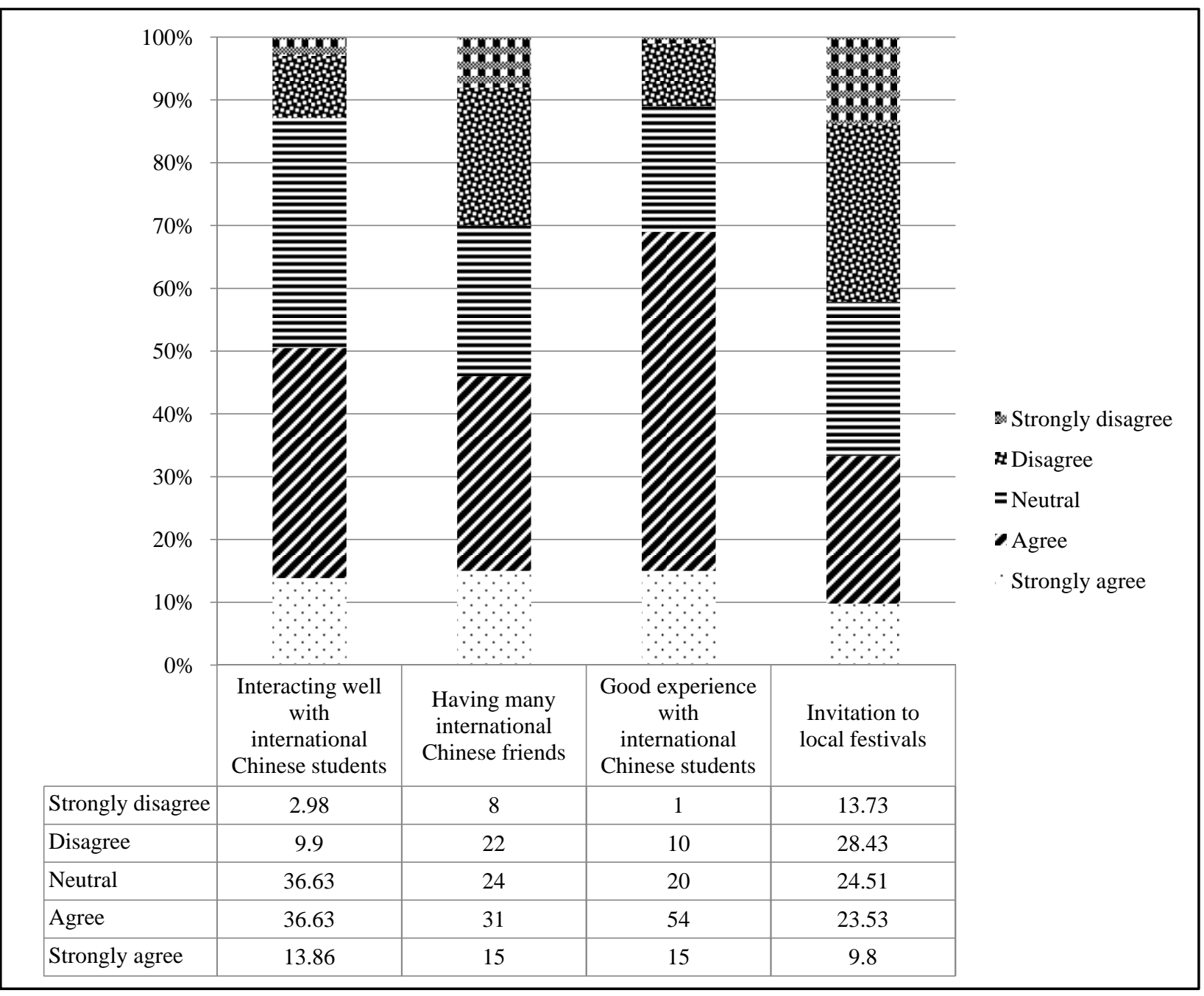

Figure 3. Singaporeans’ attitude and behavior towards international Chinese students. 


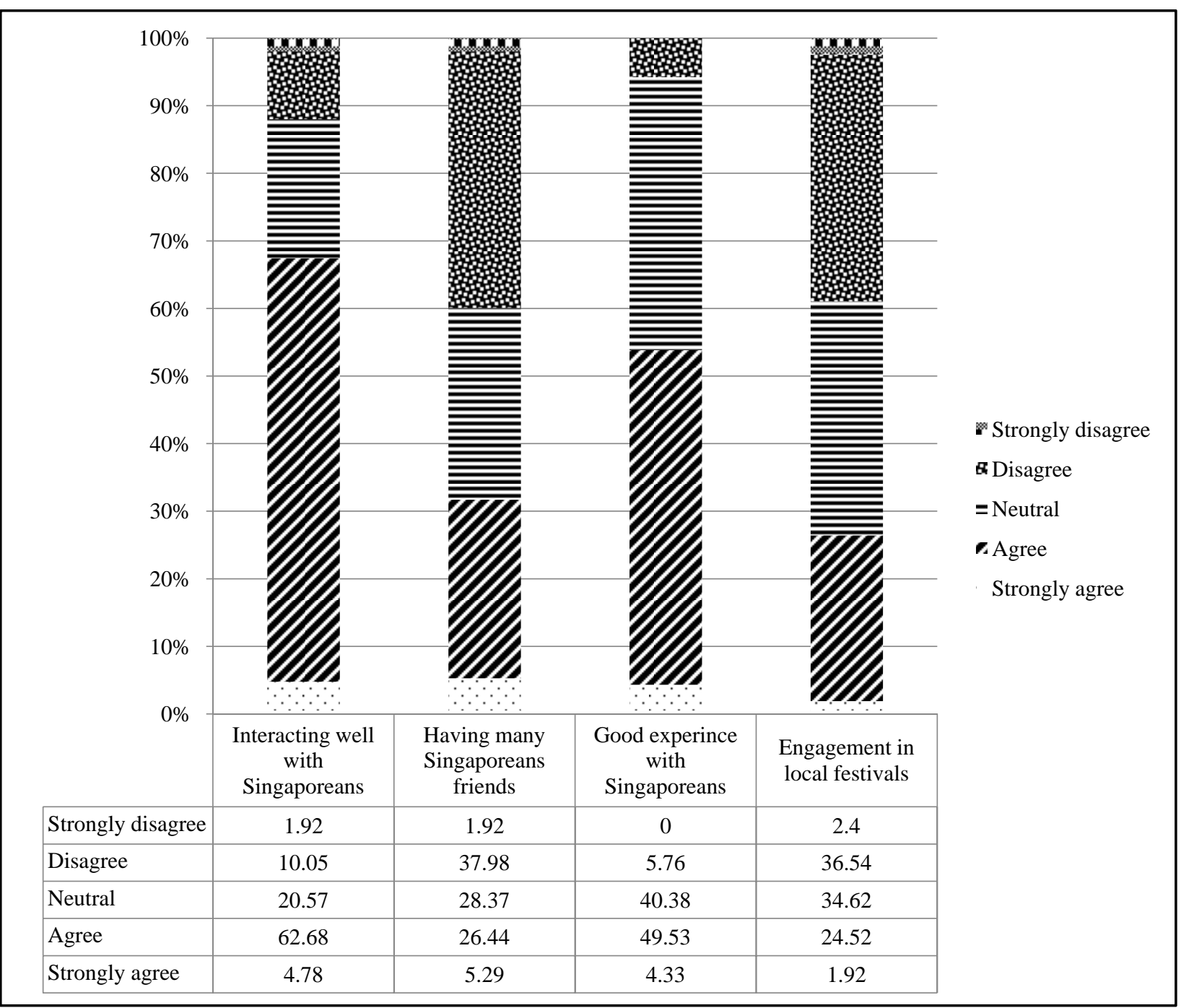

Figure 4. International Chinese students' attitude and behavior towards Singaporeans.

\section{International Chinese Students’ Interaction and Engagement in Local Festivals/Social Events}

The survey shows that $42.16 \%$ of Singaporeans had not invited international Chinese students to come to their community festivals (see Figure 3), which resulted in the fact that $38.94 \%$ international Chinese students had never engaged in any local festivals or social activities (see Figure 4). Just $26.44 \%$ joined those activities several times. Amongst them, the number of females taking part in social events and having good rapport with locals was higher than that of males. Also, most feedbacks from local Singaporeans stated that:

I rarely saw the Chinese international students and local Chinese interacting in any events. The Chinese international students always hang out in their own clique.

One of the reasons for this problem is due to the gap in the lifestyles between young generations in Singapore and international Chinese students. As the former tends to adopt western culture, it is not familiar with most international Chinese students' lifestyles to get along well with Singaporeans. On the other hand, the old generations who share the similar cultures with international Chinese students are not willing to invite them to participate in local events because of generation gap. 
The results of the interviews also point out that the more they stayed in Singapore, the more friends they had but with low interest in participating in social events. For international Chinese students who had just been in Singapore for around three months, they had fewer local friends but more engagement in local activities, such as more frequently going to Chinatown, local churches, and temples and did some volunteering in order to practice speaking English and explore new places in Singapore. Noticeably, through interviews, this paper explores that if they had an intention to stay and work in Singapore after graduation, most international Chinese students would try their best to expand their networks and take part in more local social activities. Also, most participants admit that they would be likely to take part in local events if they were invited by local friends.

In addition, the research finds out that age is one of the main elements related to integration. Specifically, for international Chinese students with the age range between 13 and 16, they engaged in social activities, communicating and making friends with local Singaporeans easily. For participants aged between 17 and 25 and above, though studying at public schools and having some or many Singaporean friends, they showed no interest in taking part in local events.

\section{Factors Motivating International Chinese Students to be More Active in Interaction With Locals}

As previously mentioned, the role of friendship with local Singaporeans and career intention in Singapore are considered to be the motives related to the level of their engagement in local communities. Through interviews, the paper finds out that in terms of friendship, if they had more Singaporean friends and were invited by them to join local festivals or social events, they were likely to participate in. Getting along with local friends in such events would release their shyness and help them to interact much easier with locals.

On the other hand, international Chinese students with the purpose of finding a job in Singapore would be more active in interacting with locals and taking part in local events or social activities. Consequently, their network could be expanded and their CV would look more professional with many different social activities they have gone through. This is the main motive that most international Chinese students mentioned in the interview in terms of encouraging factors.

In addition, more than half of the total number of International Chinese students (58\%) agreed that the institutions should have responsibilities to connect them to local Singaporean community. In their opinions, some activities should be held, such as football match, competition with mix-ethnic groups, to enhance friendship and team spirit among students. As a result, there would be more chances for them to interact with Singaporean students and vice versa. Also, some international Chinese students stated that they lacked information about local events or activities, such as volunteering. Thus, in their opinion, institutions should work as a channel to deliver and advertise for the local communities events so that they could gain their awareness of such events to participate in and make friends with locals.

\section{Conclusion and Recommendation}

The conclusion can be drawn from three main issues mentioned in this paper. Firstly, when it comes to culture similarity, the result shows that the majority of participants from the two sides both agreed that they shared many common things in culture. However, both sides disagreed on the belonging sense to local Chinese community and international Chinese students also did not feel the sense of national affinity with locals as well. 
Another conclusion is about the level of integration of international Chinese students into local communities. Based on the results from survey, even the number of international Chinese students is increasing in local residential areas, not many of them actively participate in local festivals and social events when they stay in Singapore which will deduct the opportunities while interacting with the local Singaporeans. This is attributed to lacking of local friends, information about the events as well as unwelcomed feelings in such activities.

In addition, it is believed that role of friendship, institution, and career intention have a significant influence on the level of integration of international Chinese students into local communities. Most respondents emphasized that they would be likely to join such activities if they had information timely, and were invited by local friends. Also, institution works as an encouragement for them to be more active in interacting with locals. Above all, intention of working in Singapore is considered to be the main factor for them to engage in local activities to expand their network.

In order to help international Chinese students interact with the locals well, there are some suggestions given to the stakeholders. Firstly, both institutions and Chinese Embassy in Singapore need to do research to find out which local social activities such as festivals, events they are most interested in. Universities or education institutions should enhance the integration of international Chinese students in campus activities, through sports, cultural activities, and drama classes to encourage the involvement of both local Singaporeans and international Chinese students. In addition, they should launch competitions which require the participation of both international Chinese students and Singaporean students to enhance the integration of international Chinese students in study environment. By encouraging them to work with other nationalities, it will discourage them from staying within their own country group.

Secondly, the local government plays a very important role in encouraging international Chinese students to interact with the locals. Singapore government should express the willing that all international students have opportunities to be volunteers and integrate into festival celebrations with the local students. At cross-cultural events, international student volunteers come together to showcase different cultures through games, dance, and food. In addition, some cultural tours such as visits to places of worship or ethnic enclaves like Chinatown and Little India should be held. Through these social events and festivals, international students in general and international Chinese students particularly will have chances to get closer to local students and communities.

Thirdly, it is known that integration is a mutual process that needs efforts coming from both sides to have desired results. For international Chinese students in Singapore, they should be more active in taking part in local events or social activities. This fosters cross-cultural understanding and allows students to appreciate how similar festivals can be celebrated in different countries. Meanwhile, students are given opportunities to understand and appreciate Singapore's history, heritage, and diversity.

Like every research project, this paper has its own limitations. Because of the time constraints, we just had two weeks to conduct the survey. Although, using online survey would be convenient to collect and analyze data, we did not have enough respondents to participate in our survey. As a result, we printed out the survey and went out to ask people to do the survey. This could get more respondents, but it was a hard job for us to import the data into the online technique. For results, we did not adopt SPSS systems to analyze the data as we focus more on the relationship and attitudes towards the two mentioned subjects. 


\section{References}

Bun, C. K., \& Sing, S. C. (2003). Migrant family drama revisited: Mainland Chinese immigrants in Singapore. Sojourn: Journal of Social Issues in Southeast Asia, 18(2), 171-200. doi: 10.1355/SJ18-2A

Dimmock, C., \& Leong, J. O. S. (2010). Studying overseas: Mainland Chinese students in Singapore. Compare: A Journal of Comparative and International Education, 40(1), 25-42. doi: 10.1080/03057920903155666

Embassy of the Republic of Singapore. (2012). Studying in Singapore. Retrieved from http://www.mfa.gov.sg/content/mfa/overseasmission/brussels/about_singapore/studying_in_singapore.html

Hodkinson, C. S., \& Poropat, A. E. (2014). Chinese students' participation: The effect of cultural factors. Education and Training, 56(5), 430-446.

Khanna, V. C. (2001). The Chinese Diaspora. China Report, 37(4), 427-443. doi: 10.1177/000944550103700401

Lai, W. L. (2004). Chinese diasporas: An overview. Caribbean Quarterly, 50(2), 1-14.

Liu, G., \& Ryan, C. (2011). The role of Chinese students as tourists and hosts for overseas travel. Asia Pacific Journal of Tourism Research, 16(4), 445-464. doi: 10.1080/10941665.2011.588877

Liu, H. (2014). Beyond co-ethnicity: The politics of differentiating and integrating new immigrants in Singapore. Ethnic and Racial Studies, 37(7), 1225-1238. doi: 10.1080/01419870.2014.892630

Mackie, J. (2003). Thinking about the Chinese overseas. American Asian Review, 21(4), 1-44.

Merson, J. (1989). Roads to Xanadu: East and West in the making of the modern world. London: George Weidenfeld \& Nicolson.

Singapore Government. (2014). Statistics Singapore: Population and population structure. Retrieved from http://www.singstat.gov.sg/statistics/browse_by_theme/population.html

Song, E., \& Lim, C. L. (2001). Pre-enlistment lifestyle and physical fitness of young Singaporean male adults. Medicine \& Science in Sports \& Exercise, 33(5), S238. doi: 10.1097/00005768-200105001-01335

Steele, K. D. (2008). Perceptions of Chinese international students in Singapore: Adjustment issues and support. ProQuest, UMI Dissertations Publishing.

Tsang, E. W. K. (2001). Adjustment of mainland Chinese academics and students to Singapore. International Journal of Intercultural Relations, 25(4), 347-372. doi: 10.1016/S0147-1767(01)00010-4

UNESCO. (2006). Institute of statistics: Global education digest in 2006. Retrieved from http://www.uis.unesco.org/ev.php?ID=6513_201\&ID2=DO_TOPIC

Zhang, J. (2001). Exploring variability in language anxiety: Two groups of PRC students learning ESL in Singapore. RELC Journal, 32(1), 73-91. doi: 10.1177/003368820103200105 